\title{
COMPARISON OF ELISA WITH UHPLC-ESI- MS/MS METHOD FOR THE DETERMINATION OF AFLATOXIN M IN MILK
}

\author{
Arieta Camaj Ibrahimi ${ }^{1}$, Tahir Arbneshi ${ }^{2}$, Karsten Meyer $^{3}$, Bajram Berisha ${ }^{3,4}$, \\ Zehra Hajrulai-Musliu ${ }^{5}$, Arben Haziri ${ }^{2}$, Aferdita Camaj Isa ${ }^{6 *}$ \\ ${ }^{1}$ University of Peja "Haxhi Zeka", Department of Food Technology, Peja, 30000, Kosovo; \\ ${ }^{2}$ University of Prishtina "Hasan Prishtina", Department of Chemistry, Prishtina, 10000, Kosovo; \\ ${ }^{3}$ Technical University of München, Institute of Animal Hygiene, Freising 85354, Munich, Germany; \\ ${ }^{4}$ University of Prishtina "Hasan Prishtina", Department of Biotechnology, Prishtina, 10000, Kosovo; \\ ${ }^{5}$ University "Ss. Cyril and Methodius", Faculty of Veterinary Medicine, Skopje, 1000, North Macedonia; \\ ${ }^{6 *}$ Kosova Medicines Agency, Prishtina, Kosovo;
}

"Corresponding author: Aferdita Camaj Isa, e-mail address: aferditacamaj@gmail.com; arieta.camajibrahimi@unhz.eu;

Received March 2021; Accepted May 2021; Published June 2021;

DOI: https://doi.org/10.31407/ijees11.331

\begin{abstract}
Aflatoxin $\mathrm{M}_{1}$ is a hydroxylated metabolite excreted in milk, which is considered as a potent health risk factor for consumers, therefore, the routine control of this toxin is essential. To monitor the concentration of this toxin, during this study are used and compared to each other for the correlation, two methods, the competitive method ELISA and UHPLC-ESI-MS/MS as a confirmative method. According to the results found using the two methods, from 192 of raw cow's milk samples analyzed, about $40 \%$ of samples resulted positive with $\mathrm{AFM}_{1}$, among them, $6.5 \%$ of the samples exceeded the maximum tolerable level according to ELISA method, and $5.5 \%$ of the samples according to UHPLC-ESI-MS/MS. In conclusion, the results of this study suggest that there is a good correlation between the two methods used. The UHPLC-ESI-MS/MS method requires longer time of determination than ELISA method because there is the need of the extraction of milk samples for $\mathrm{AFM}_{1}$ by the immunoaffinity columns ahead of quantitative analysis.
\end{abstract}

Key words: Aflatoxin $\mathrm{M}_{1}$, Milk, ELISA, UHPLC-ESI- MS/MS, Comparison 